\title{
Five-year Survival Rate for Gastric Cancer in Yazd Province, Central Iran, from 2001 to 2008
}

\author{
Mohsen Akhondi-Meybodi ${ }^{*}$, Marzieh Ghane ${ }^{2}$, Sara Akhondi-Meybodi ${ }^{2}$, Golnaz Dashti ${ }^{3}$
}

1. Associate Professor, Department of Internal Medicine, Subspecialty in Gastroenterology and Hepatology, ShahidSadoughi University of Medical Sciences, Yazd, Iran

2. Medical Student, Member of Student Research Committee, ShahidSadoughi University of Medical Sciences, Yazd, Iran

3. General Practitioner, ShahidSadoughi University of Medical Sciences, Yazd, Iran

\footnotetext{
* Corresponding Author:

Mohsen Akhondi-Meybodi,MD Department of Internal Medicine, Subspecialty in Gastroenterology and Hepatology, Shahid Sadoughi University of Medical Sciences, Yazd, Iran Tel: + 983538224000 Fax: + 98358224100 Email: akhondei@gmail.com
}

Received: 05 Jun. 2016 Accepted: 25 Oct. 2016

\section{ABSTRACT}

\section{BACKGROUND}

The number of patients with gastric cancer is growing worldwide. In Iran (in 2009) of 74067 new cases of cancer, 6886 were diagnosed as having gastric cancer. This study was conducted to investigate 5-year survival rate for gastric cancer in Yazd province, central Iran.

\section{METHODS}

In this descriptive study, the medical records of patients with gastric cancer were collected from the archives of Yazd hospitals from 2001 to 2008. The data gathered included age, sex, type of histopathology, site of involvement, cancer staging, and mode of treatment, which were analyzed using SPSS software version 11.5. To investigate the survival and the factors influencing the survival time of patients, which are the main objectives of this study, Kaplan-Meier method was used and Cox proportional hazards model was fitted to the data. To compare survival function in different subgroups, the log rank test or generalized Wilcoxon test was used.

\section{RESULTS}

295 cases of gastric cancer were enrolled in the study. The mean age of the subjects was $59.3 \pm 9$ years. 5-year survival rate of the patients was calculated as $18 \%$ where the highest rate was $39 \%$ for the age group of 50-60 years and the lowest was 3\% for the age group of above 80 years. 5-year survival rates in different groups were as follows: $32 \%$ in women, $13 \%$ in men; $16 \%$ in adenocarcinoma, $46 \%$ in other pathologies; $16 \%$ in gastric cardia involvement, $17 \%$ in antrum; $59 \%$ in stage $1,31 \%$ in stage $2,13 \%$ in stage 3 , and $3 \%$ in stage 4 .

\section{CONCLUSION}

The results of this study showed that age, stage of the cancer, mode of therapy, and type of histopathology affected the survival rate of gastric cancer. No significant association was found between the site of involvement and survival rate. In general, the survival rate for gastric cancer was low, which might be due to slow but steady progress of the disease and delayed referral of the patients.

KEYWORDS: Gastric cancer, Survival rate, Iran

Please cite this paper as:

Akhondi-Meybodi M, Ghane M, akhondi-Meybodi S, DashtiG. Five-year Survival Rate for Gastric Cancer in Yazd Province, Central Iran, from 2001 to 2008. Middle East J Dig Dis 2017;9:39-48. DOI: 10.15171/mejdd.2016.50

\section{INTRODUCTION}

Gastric cancer is known as one of the common causes of cancer mortality worldwide. ${ }^{1}$, as of 74067 new cases of cancer in Iran in 2009, 6886 were de- 
tected as having gastric cancer. ${ }^{2}$ Gastric cancer is the second most prevalent malignancy in men (after skin cancer), and the fourth in women (after breast, skin, and colon and anal canal cancers) in the world. ${ }^{2}$ In Iran in 2006, gastric cancer accounted for $7.5 \%$ of all cancers in men and 5.4\% in women. 1679 cases of gastric cancer were reported in women and 4386 cases in men. The incidence of this type of cancer differs country by country, which is 26.1 and 11.1 per 100,000 individuals in men and women, respectively. ${ }^{3-4}$ According to the latest reports of the Iranian Ministry of Health and Medical Education, gastric adenocarcinoma has been introduced as the most fatal cancer in Iran. ${ }^{2}$ The disease usually starts in the fourth decade of life and its incidence increases by age. In other words, the highest prevalence is found at the 7 th decade of life in men and particularly older ages in women. ${ }^{3}$ Approximately $75 \%$ of the patients were presented at the advanced metastatic stages. ${ }^{5}$ Several prognostic factors affect the patients' life span, of which the stage of disease and age have been the most important ones. $^{4-6} 5$-year survival rate for this disease was $10-30 \%$ in European countries, which was similar to the United States with a rate of $15-18 \%{ }^{5}$ About two third of the patients refer to physicians at the advanced stages of the disease, which makes the therapeutic interventions difficult hence surgery is proposed as the main treatment for such patients. ${ }^{2,3,7,8}$ In this study the survival rate of patients with gastric cancer was examined from 2001 to 2008 in Yazd in terms of age, sex, type of histopathology, site of involvement, cancer staging, and treatment.

\section{MATERIALS AND METHODS}

In this descriptive retrospective study the medical records of patients with gastric cancer including their records of pathology, endoscopy, and surgery reports were collected from the archives of Yazd hospitals from 2001 to 2008. In total, 350 records were evaluated of which 330 had complete information. The required information regarding age, sex, type of histopathology, site of involvement, cancer staging, treatment, and contact information were gathered. The recent health status of 295 patients was assessed through telephone call. Regarding the limitation in detecting the cause of death via telephone call, the cause of death was considered to be different, not just because of gastric cancer. The survival rate was calculated as the rate of being alive after the first diagnosis to the death time. Data analysis was carried out using SPSS software version 11.5 and statistical log-rank (Mantel-Cox) survival rate for patients with gastric cancer. To investigate the survival rate and the factors affecting the survival time of the patients, which were the main objectives of this study, Kaplan-Meier method was used and Cox proportional hazards model was fitted to the data.

\section{RESULTS}

The patients of this study consisted of 295 patients with gastric cancer (207 men and 88 women) living in Yazd province, central part of Iran from 2001 to 2008. 176 out of the 295 subjects were from city of Yazd (the administrative center of the province) and the remaining 119 patients have been referred from other cities of the Yazd province. Mean age was 59.3 \pm 9 years. Regarding pathological aspects, $94 \%$ of the patients had adenocarcinoma and $6 \%$ presented other pathologies (table 1).

In the present study gastric cancer survival was evaluated by age. The highest survival was observed in the age group of 50-60 years, whereas those above 80 years of age had the lowest survival rate. 5-year survival rate was 39\% for the age group of 50-60 years and, 3\% for those above 80 years, which the difference was statistically significant ( $p=0.001$, figure 1 ). Also this rate was $32 \%$ in women and $13 \%$ in men. Mean and median of survival rate were, 33 and 20 months for women, and 21 and 15 months for men, respectively which was statistically significant ( $p=0.001$, figure 2 ).

According to the results of this study, $94 \%$ of the gastric cancers were adenocarcinoma, 4\% were lymphoma, and $1.5 \%$ was squamous cell carcinoma (SCC). Regarding the type of histopathology, 5-year survival rate was $16 \%$ in adenocarcinoma, $42 \%$ in lymphoma, and $36 \%$ in $\operatorname{SCC}(p=0.001$, figure 3$)$.

In this study, cardia was the most frequent site of involvement followed by antrum. 5-year survival rate was $16 \%$ when cardia was involved, and $17 \%$ when the tumor was located in the antrum (figure 4).

The information related to the tumor stage was available for 244 patients out of the 295. The results of this study indicated that cancer stage could significantly af- 
Table 1: Characteristic of the patients with gastric cancer in Yazd province

\begin{tabular}{|c|c|c|c|c|c|c|c|c|c|}
\hline \multicolumn{3}{|c|}{ Variables } & $\begin{array}{c}\text { 5-year } \\
\text { survival }\end{array}$ & $\begin{array}{c}\text { Survival } \\
\text { mean } \\
\text { (months) }\end{array}$ & $\begin{array}{c}\text { Survival } \\
\text { median } \\
\text { (months) }\end{array}$ & Number & Alive & Dead & $P$ value \\
\hline \multirow{2}{*}{\multicolumn{2}{|c|}{ Sex }} & Male & $13 \%$ & 214 & 13 & 207 & 36 & 171 & \multirow{2}{*}{0.001} \\
\hline & & Female & $17 \%$ & 33 & 20 & 88 & 32 & 56 & \\
\hline \multirow{5}{*}{\multicolumn{2}{|c|}{ Age (years) }} & Below 50 & $26 \%$ & 34 & 20 & 52 & 20 & 32 & \multirow{5}{*}{0.001} \\
\hline & & $50-60$ & $39 \%$ & 48 & 70 & 46 & 27 & 19 & \\
\hline & & $60-70$ & $14 \%$ & 27 & 20 & 71 & 19 & 52 & \\
\hline & & $70-80$ & $7 \%$ & 12 & 9 & 76 & 2 & 74 & \\
\hline & & 80 and above & $3 \%$ & 7 & 6 & 50 & 0 & 50 & \\
\hline \multirow{7}{*}{$\begin{array}{l}\text { Mode } \\
\text { of } \\
\text { therapy }\end{array}$} & \multirow{2}{*}{ Surgery } & + & $20 \%$ & 29 & 17 & 216 & 89 & 157 & \multirow{2}{*}{0.001} \\
\hline & & - & $12 \%$ & 15 & 8 & 76 & 6 & 70 & \\
\hline & \multirow{2}{*}{ Chemotherapy } & + & $30 \%$ & 36 & 20 & 187 & 68 & 119 & \multirow{2}{*}{$0 / 0015$} \\
\hline & & - & 0 & 8 & 8 & 108 & 0 & 108 & \\
\hline & \multirow{3}{*}{ Radiotherapy } & + & $9 \%$ & 20.6 & 17 & 43 & 11 & 32 & \multirow{3}{*}{0.59} \\
\hline & & - & $19 \%$ & 26.6 & 14 & 252 & 57 & 195 & \\
\hline & & - & & & & & & & \\
\hline \multirow{4}{*}{\multicolumn{2}{|c|}{ Stage of disease }} & 1 & $59 \%$ & 67 & 42 & 58 & 41 & 17 & \multirow{4}{*}{0.001} \\
\hline & & 2 & $31 \%$ & 28 & 23 & 28 & 12 & 16 & \\
\hline & & 3 & $13 \%$ & 17 & 18 & 60 & 12 & 48 & \\
\hline & & 4 & $3 \%$ & 7 & 8 & 149 & 3 & 146 & \\
\hline \multirow{5}{*}{\multicolumn{2}{|c|}{ Site of involvement }} & cardia & $16 \%$ & 23 & 15 & 117 & 25 & 92 & \multirow{5}{*}{0.23} \\
\hline & & antrum & $17 \%$ & 23 & 10 & 84 & 18 & 66 & \\
\hline & & fundus & $40 \%$ & 35 & 18 & 15 & 6 & 9 & \\
\hline & & greater curvature & $20 \%$ & 28 & 18 & 30 & 9 & 21 & \\
\hline & & lesser curvature & $18 \%$ & 23 & 13 & 32 & 7 & 25 & \\
\hline \multirow{5}{*}{\multicolumn{2}{|c|}{ Type of histopathology }} & adenocarcinoma & $16 \%$ & 24.4 & 14 & 273 & 57 & 216 & \multirow{5}{*}{0.001} \\
\hline & & lymphoma & $42 \%$ & 41 & 38 & 14 & 9 & 5 & \\
\hline & & leiomyoma & - & - & - & 1 & 0 & 1 & \\
\hline & & MALToma & - & - & - & 1 & 0 & 1 & \\
\hline & & $\mathrm{SCC}$ & 36 & 36 & 31 & 6 & 2 & 4 & \\
\hline
\end{tabular}

SCC: Squamous Cell Carcinoma, MALT: Mucosa-associated lymphoid tissue (MALT) lymphomas

fect the survival rate where it was $59 \%$ in stage one, $31 \%$ in stage two, $13 \%$ in stage three, and only $3 \%$ in stage four ( $p=0.001$, figure 5 ).

In the current study, 5-year survival rate was $20 \%$ for the patients undergoing surgery and $12 \%$ for those receiving non-surgical management. Mean and median of survival were 29 and 17 months for surgical management, and 15 and 8 months for non-surgical management, respectively, which was statistically significant ( $p=0.001$, figures 6-7).

5 -year survival rate was $30 \%$ using chemotherapy versus $0 \%$ for non-chemotherapy (figure 7). 5-year survival rate by radiotherapy was $9 \%$, while it was $19 \%$ for non-radiotherapy treatment (figure 7).

\section{DISCUSSION}

In the present study, survival rate for gastric cancer was investigated from 2001 to 2008 in Yazd province. 5 -year survival rate was calculated as $18 \%$. Gastric cancer is considered as a common cancer in Yazd province with a mean morbidity age of $59.3 \pm 9$ years. According to the results of this study, age, stage of the disease, mode 


\section{Survival Functions}

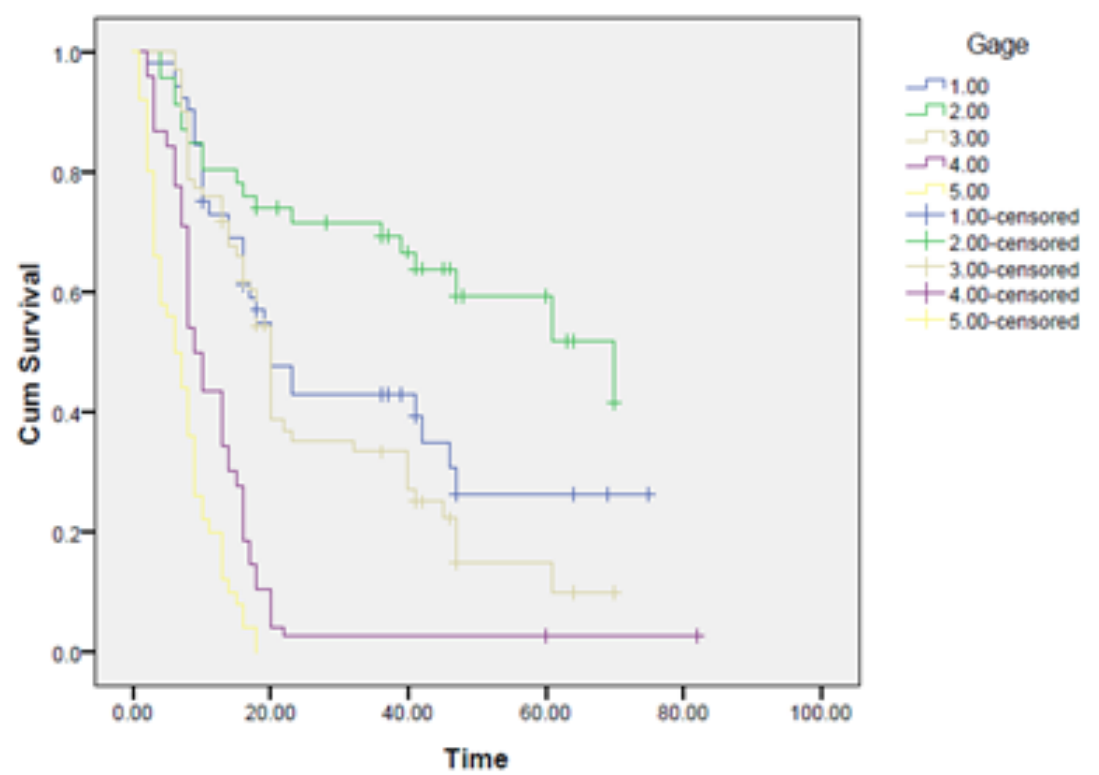

Fig.1: Association between age and survival rate for gastric cancer using log-rank (Mantel-Cox) test.

\section{Survival Functions}

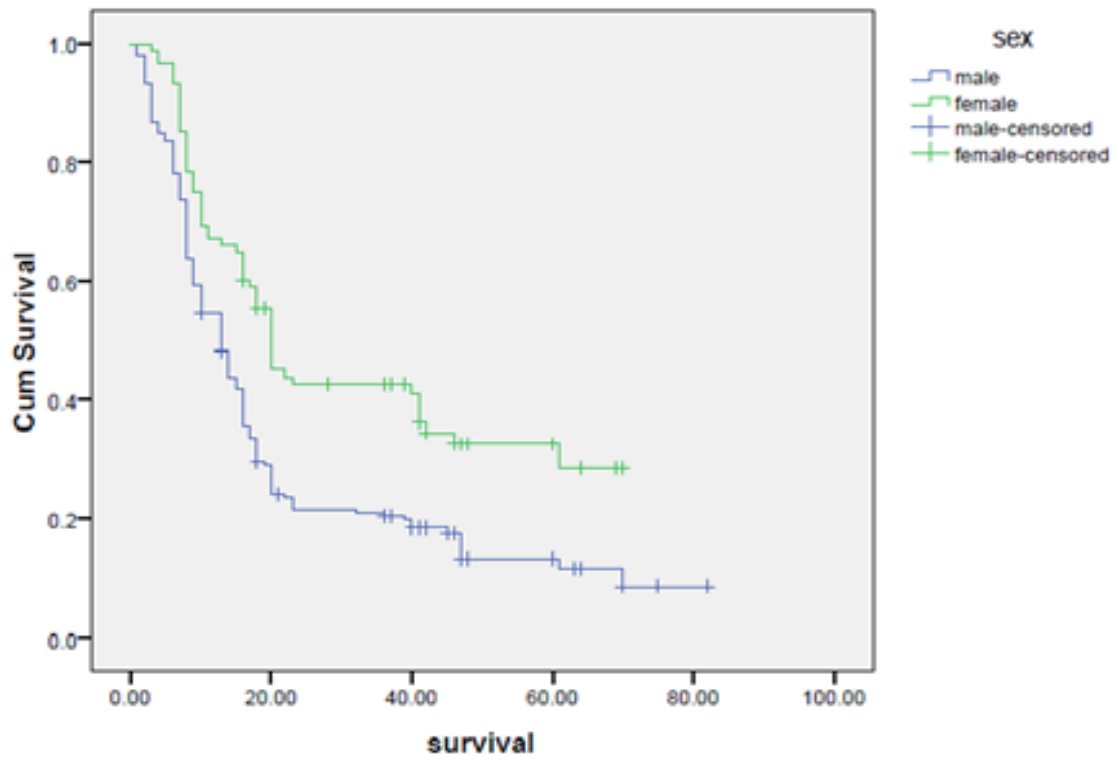

Fig.2: Association between sex and survival rate for gastric cancer using log-rank (Mantel-Cox) test 


\section{Survival Functions}

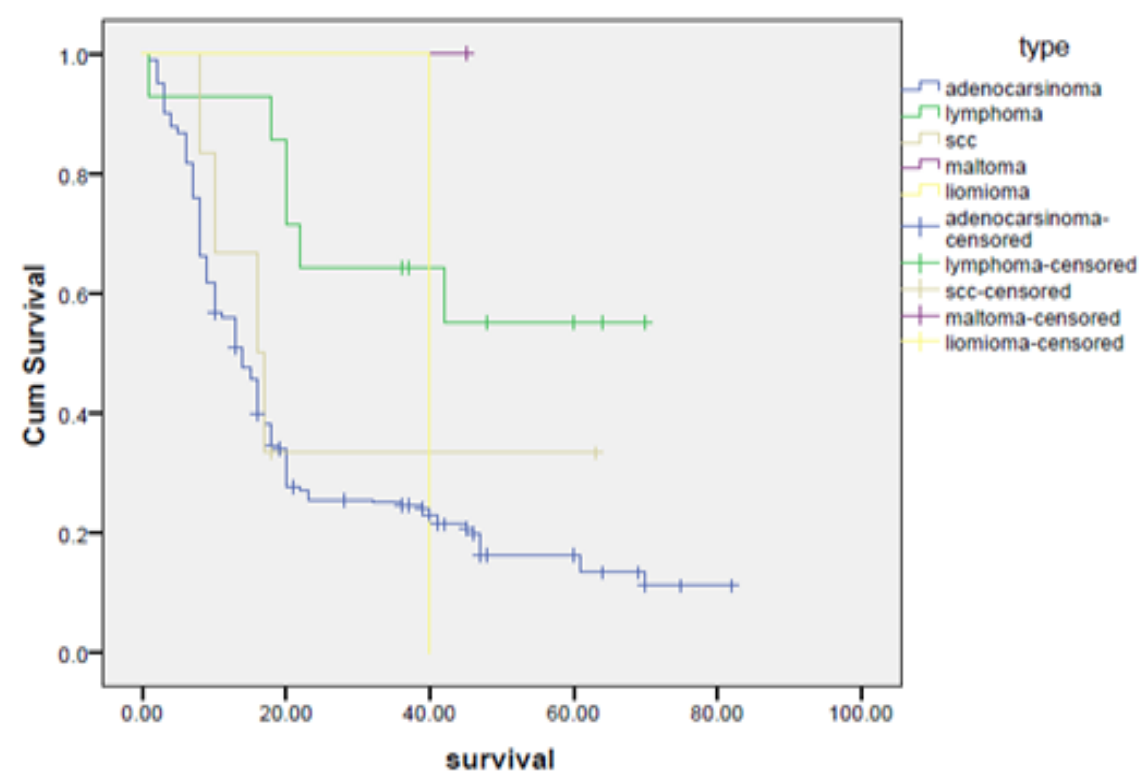

Fig.3: Associationbetween the type of histopathology and survivalrate for patients with gastric cancer using log-rank (Mantel-Cox)

\section{Survival Functions}

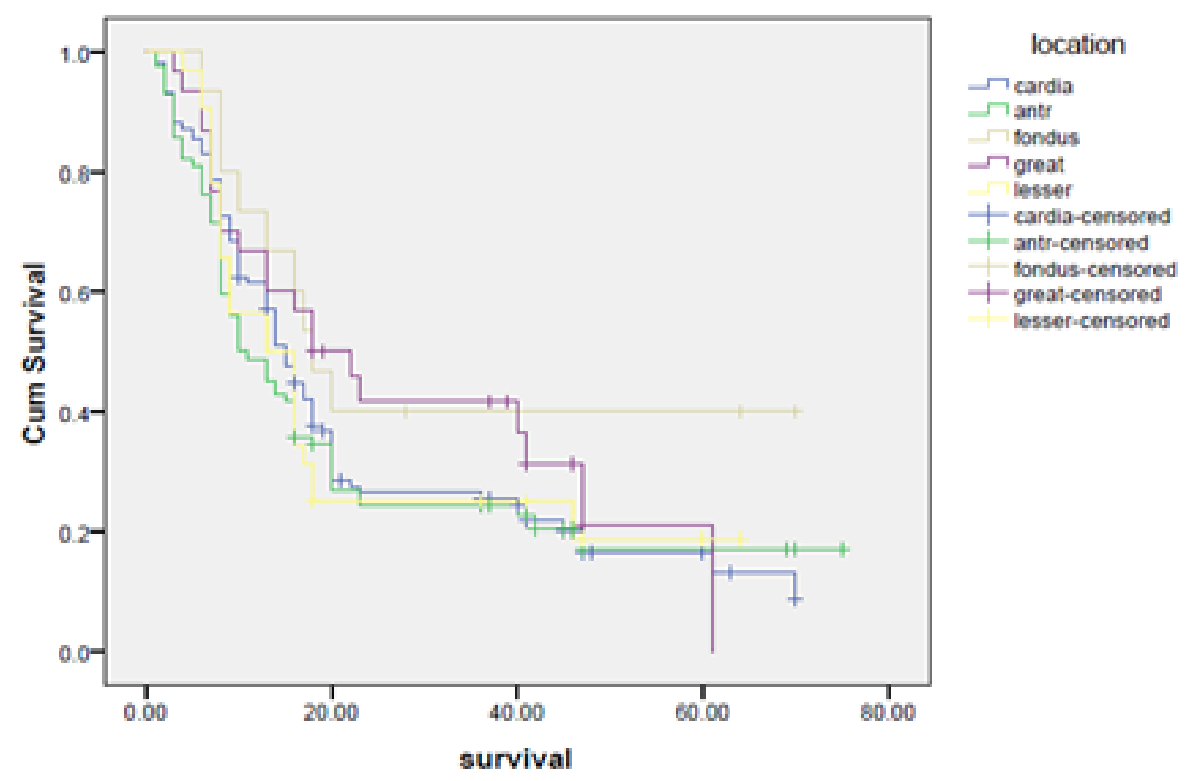

Fig.4: Association between the site of involvement and survival rate for patients with gastric cancer using log-rank (Mantel-Cox) 


\section{Survival Functions}

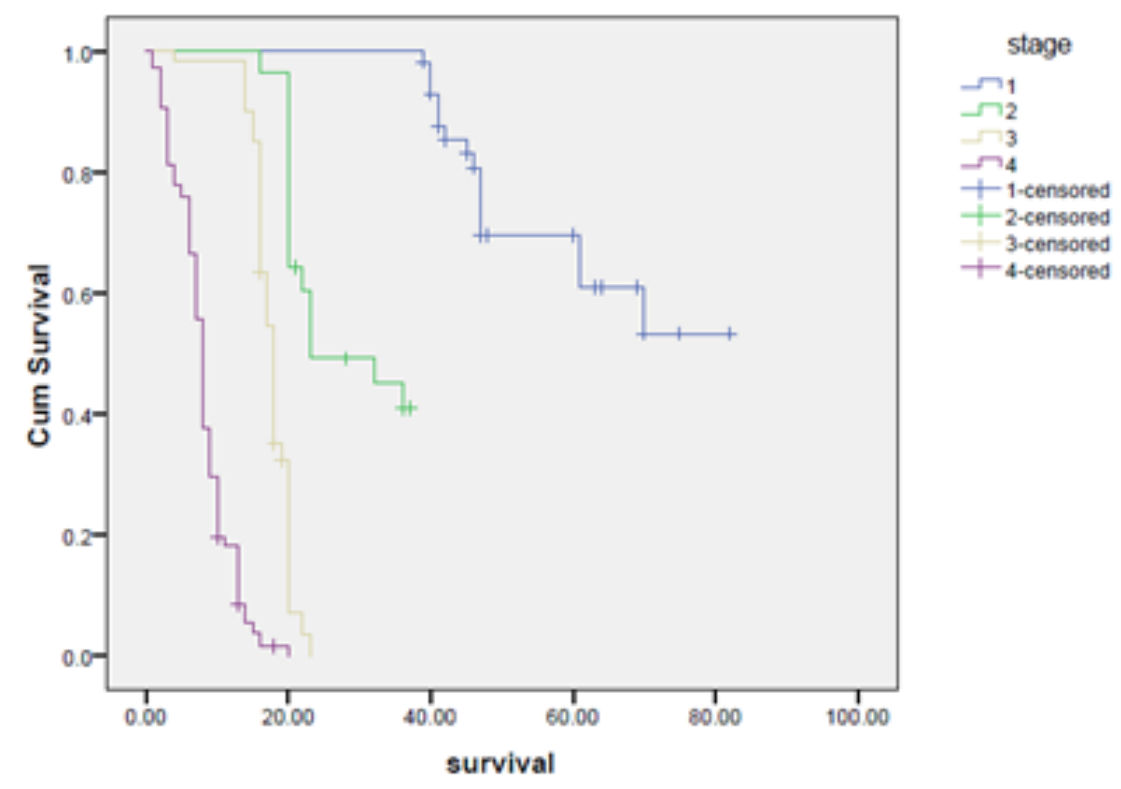

Fig.5: A: Association between the stage of cancer and survival rate for patients with gastric cancer using log-rank (Mantel-Cox)

\section{Survival Functions}

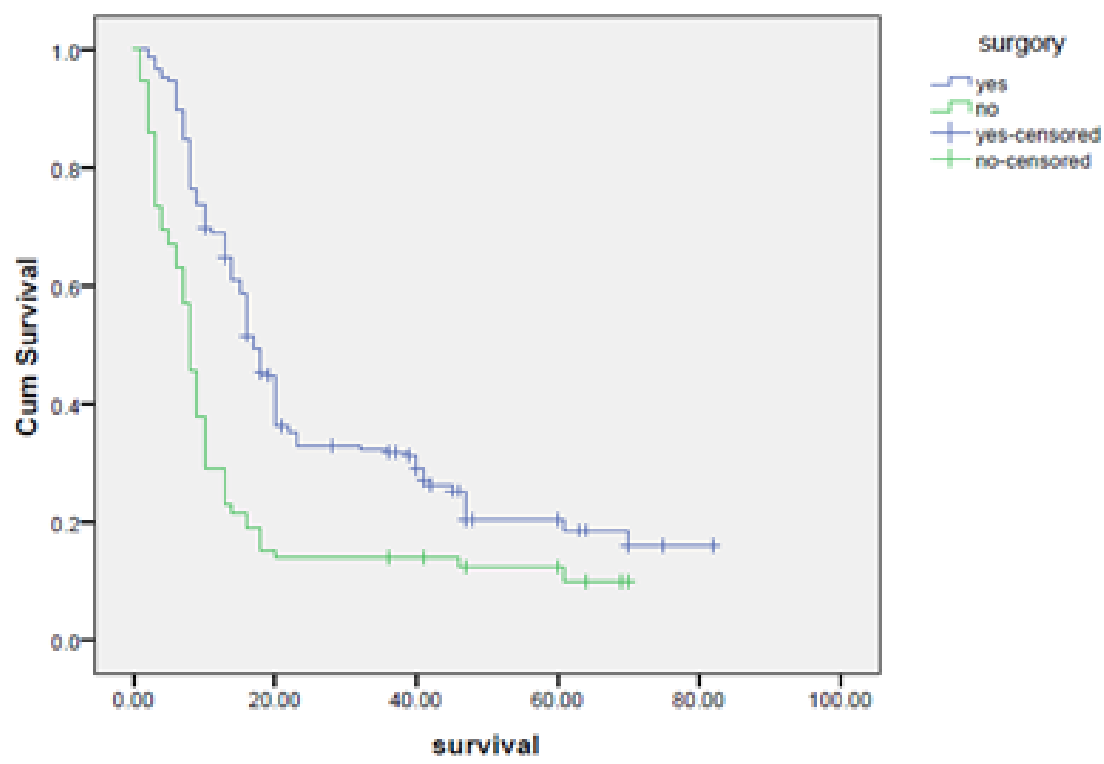

Fig.6: Association between surgery and survival rate for patients with gastric cancer using log-rank (Mantel-Cox) test 


\section{Survival Functions}

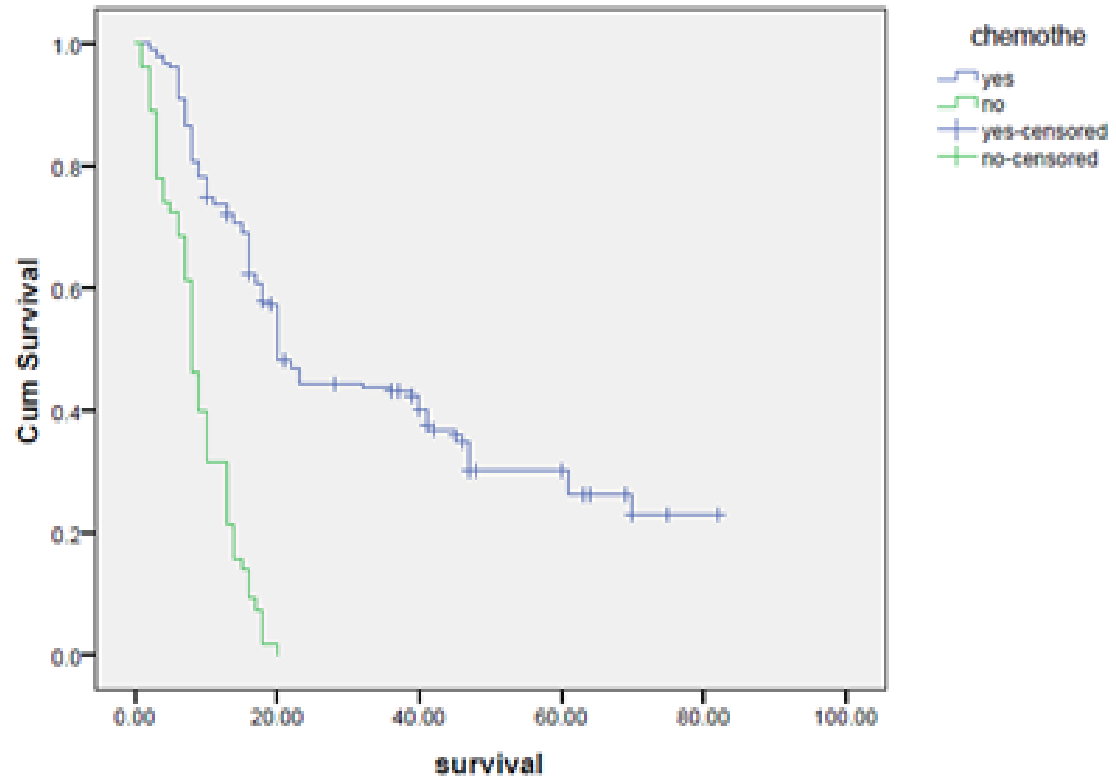

Fig.7: Association between chemotherapy and survival ratefor patients with gastric cancer using log-rank (Mantel-Cox) test

\section{Survival Functions}

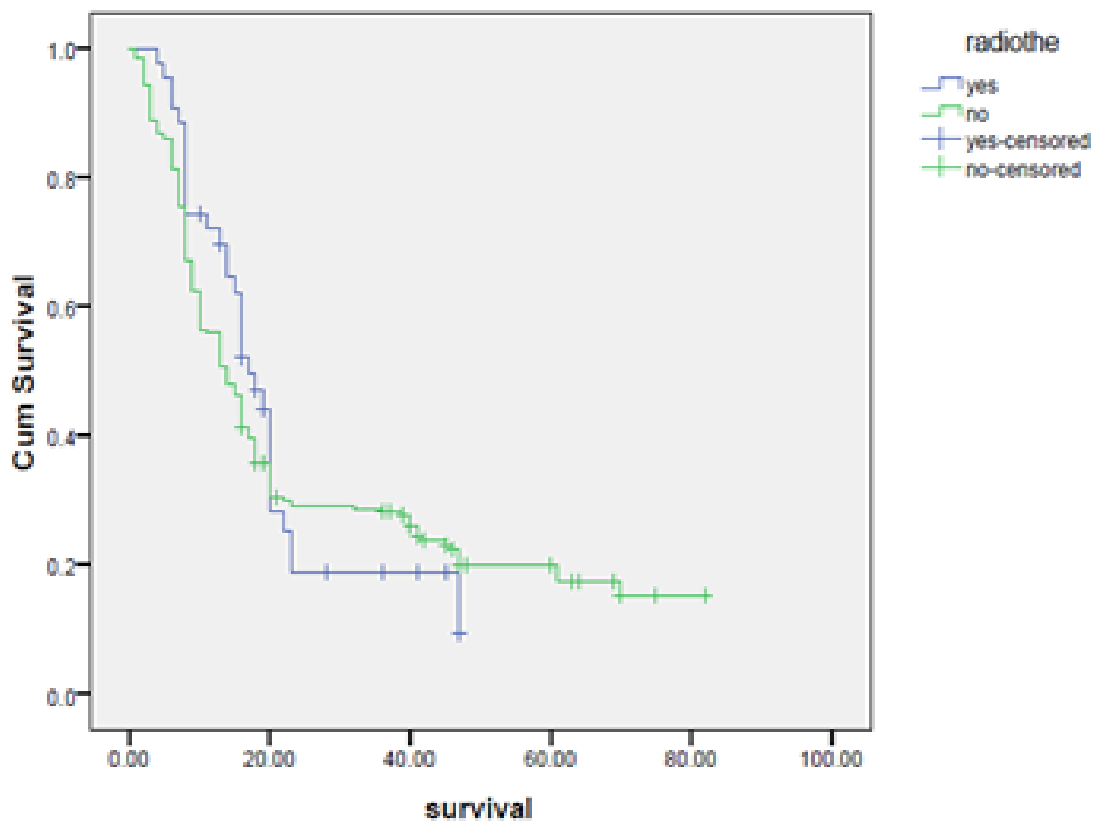

Fig.8: Association between radiotherapy and survival rate for patients with gastric cancer using log-rank (Mantel-Cox) 
of therapy, and type of histopathology were effective in the survival rate of patients with gastric cancer, whereas, no significant association was found between the site of involvement and survival rate.In a study in England, Ditlemarier announced that in 1970 and 2001, 5-year survival rates were $4 \%$ and $18 \%$, respectively. ${ }^{10}$ In a similar study by Biglarian, survival rate was reported as $12 \%{ }^{9}$ In other studies 5-year survival rate of cancer of cardia remained about $10 \%$ while it decreased in non-cardia cancers (14-22\%). ${ }^{9}$ In a recently published meta-analysis in Iran, 5-year survival rate of gastric cancer was $17 \%$ in Iran (95\% CI: 0.13-0.21), and 24\% in the United States. ${ }^{11}$

The highest survival rate was observed in the fifth decade of life and the worst was in patients aged above 80 years. In a similar study by Biglarian, the highest survival rate belonged to the age group of 45-60 years and the lowest to $<50$ years of age. ${ }^{14}$ The previous studies had considered age as an effective factor in survival rate. ${ }^{10}$ In most research, the lowest rate of survival for gastric cancer can be seen in ages $<50$ and $>80$ years, while the highest survival is related to the age group of 50-64 years. ${ }^{3,6}$ The findings of this study were consistent with such results. One explanation for the lowest survival in age less than 50 years may be due to histological type "diffuse type" which is more common in juvenile than intestinal type that worsens the prognosis, or may be the delay in diagnosis due to low suspicious that leads to diagnosis in higher stage.

5-year survival rate was significantly longer in women than men. In many studies prognosis has been better in women than men. ${ }^{15}$ In another study, the survival rate of gastric cancer was 32\% in men and $33.7 \%$ in women. ${ }^{6}$ in that study, Yazdanbod found mean and median of survival rate to be 21 and 14 months for women, and 12 and 9 months for men, respectively, which was statistically meaningful $(\mathrm{p}<0.05)$. He reported higher survival rate in women compared with men. ${ }^{13}$ In most studies no considerable association was observed between the survival rate and sex, while the present study did not support these findings. Higher survival rate of women in our study can be explained by greater number of women in the age group of 50-60 years (with the highest survival rate), less types of adenocarcinoma compared with other types of histopathologies in the time of study, and earlier presentation for treatment in women.

In the present study, like other studies, most of gastric cancers were adenocarcinoma that has poorer prognosis compared with other histopathologies. Ditlemarier carried out a similar study in which adenocarcinoma was accounted for $92 \%$ of the pathologies while the remaining $8 \%$ were associated with other types. 5-year survival rate was, $36 \%$ in adenocarcinoma, and $42 \%$ in other pathologies. ${ }^{10}$ Many studies agreed that survival rate for gastric cancer was lower in adenocarcinoma compared with other types, which was confirmed by our results as well (figure 3).

In the present study, cardia was the most frequent site of involvement followed by antrum. 5-year survival rates were nearly similar and did not differ significantly. According to Yazdanbod, the site of tumor was cardia in $45 \%$ of the cases and was antrum in $21.9 \%$. 5-year survival rate was reported as $8 \%$ in cardia involvement and $14 \%$ in antrum involvement, which was not statistically significant. ${ }^{13}$ DitleMariar indicated that survival rate was the lowest in cardia involvement compared with other sites of involvement, which was not statistically significant $(p>0.05) .{ }^{10}$ In all these studies no significant association was found between the site of involvement and survival rate, however, survival rate in cardia involvement was lower than other sites. ${ }^{3,5,6}$ In the present study, similarly there was no significant relationship ( $p=0.23)$, but in contrast with other studies, the survival rate of cardia involvement showed to be more than antrum involvement, for which no justification was found.

The results of this study indicated that cancer stage could significantly affect the survival rate. Biglarian pointed out that the median of life span for the initial, local, and distant stages were $37.8,11.8$, and 11.8 months, respectively. ${ }^{14}$ In another study, the median of life span in local and metastatic development were, 18.2, and 8.3 months, respectively, which was statistically considerable. ${ }^{15}$ Studies showed that survival in patients with gastric cancer was considerably dependent upon the stage of disease, which was in agreement with our results..$^{8-11}$

In the current study, 5-year survival rate was significantly different between patients undergoing surgery and those receiving no-surgical management. In some studies 5-year survival rate increased from $47 \%$ to $54 \%$ after 
surgery. ${ }^{6,12,13}$ Relevant studies considered surgery as a critical factor in survival rate of patients with a significant statistical association. ${ }^{11,14}$ This was supported by the present study as well and can be explained by the fact that those who underwent surgery had been in lower stages of cancer, which made surgery possible. Not receiving surgical treatment may arise from one of the following reasons: cancer is in metastatic stage in which surgical therapy is impossible, the patient is old or surgery is not possible due to background diseases or any other reason, and finally the patient does not give consent to surgery.

5-year survival rate in patients receiving chemotherapy was significantly longer than thosenot receiving chemotherapy. In a similar study, 5-year survival rate was $36 \%$ for receiving chemotherapy, versus $0 \%$ for no chemotherapy, being statistically significant $(p<01) .{ }^{4}$ Likewise, Williams and colleagues conducted a study in Italy and described chemotherapy as an effective technique for increasing the survival of the patients, which was considerable with $p=0.001 .^{15}$ Taken together, the studies have confirmed the effect of chemotherapy on the survival rate for gastric cancer. There has been a remarkable association between these two issues, which was consistent with our results.

5 -year survival rate by radiotherapy was $9 \%$ versus $19 \%$ for non-radiotherapy treatment. Considering more toxicity of chemoradiotherapy, it is better to be applied only for patients with advanced cancer. According to Biglarian, 5-year survival rate by chemoradiotherapy was $5 \%$, while it was $18 \%$ for patients receiving chemoradiotherapy alone. However, it was not statistically significant $(p=0.58) .{ }^{14}$ Research has shown no significant association between radiotherapy and survival rate, which is in agreement with our results. ${ }^{16-20}$

It is recommended to perform endoscopy at least for individuals with positive family history, the family members of the patient with gastric cancer, and the patients with dyspepsia aged above 50 years in order to detect the patients in earlier stages and consequently increase the survival rate. Despite the fact that only one tenth of the patients are diagnosed at stage 1 , which results in decreased survival rate, improving early diagnosis could help increase the survival rate.

\section{CONFLICT OF INTEREST}

The authors declare no conflict of interest related to this work.

\section{REFERENCES}

1. Siegel R, Ma J, Zou Z, Jemal A. Cancer statistics 2014, CA Cancer J Clin 2014;64:9-29. doi: 10.3322/caac.21208

2. Vakili M, Pirdehghan A, Adimi M, Sadeghian M, Akhondi M. Epidemiology and Trend of Cancer in Yazd, a Central Province of Iran, 2005-2009. J Res Health Sci 2014;14:210-3. doi:10.58/2/hepatmon. 11705

3. BabaeiM, Pourfarzi F, Yazdanbod A, Chiniforush MM, Derakhshan, MousaviMH, et al. Gastric Cancer in Ardabil, Iran - a Review and Update on . Asian Pac J Cancer Prev 2010;11:595-9.

4. Liang YX, Deng JY, Guo HH, Ding XW, Wang XN, Wang BG,et al. Characteristics and prognosis of gastric cancer in patients aged $\geq 70$ years. World J Gastroenterol 2013;19:6568-78. doi: 10.3748/wjg.v19.i39.6568.

5. Damhuis RA. Tilanus HW. The influence of age on resection rates and postoperative mortality in 2773 patients with gastric cancer. Eur J Cancer 1995;31:928-31. doi:10.1016/0959-8049(95)00075-5

6. MansfieldPF. Clinical features, diagnosis, and staging of gastric cancer www.uptodate.com (2016 UpToDate

7. Karimi P, Islami F, Anandasabapathy S, Freedman ND, Kamangar F. Gastric cancer: descriptive epidemiology, risk factors, screening, and prevention. Cancer EpidemiolBiomarkers Prev 2014;23:700-13. doi:10.1158/10559965.EPI-13-1057.

8. khedmat H, Panahian M, Amini M, Izadi M, Naseri MH, Ghayomi MH. Survival of stomach adenocarcinoma. J Mil Med 2007;9:167-77. doi:10.1016/B978-0-32303938-3.50061-0

9. Biglarian A. Hajizadeh E. Kazemnejad A,Zali M. Survival analysis of gastric cancer patients using Cox model:a five year study. Tehran Univ Med J 2009;67:317-25.

10. Manfè AZ, Segalina P, Maffei Faccioli A. Prognostic factors in gastric cancer. Our experience and review of the literature. Minerva Chir 2000;55:299-305.

11. Akhondzadeh E, Yavari P, Mehrabi Y, Kabir A. Estimates of One, Three, and Five Year Survival Rate of Patients with Gastric Cancer in Iran. Iran J Epidemiol 2015;11:1-12.

12. Hundah S, Philips J, Menck H. The National Cancer Data Base Report on poor survival of U.S. gastric carcinoma patients treated with gastrectomy: 5th ed. American Joint Committee on Cancer staging, proximal disease, and the "different disease" hypothesis. Cancer 200;88:921-32.

13. Yazdanbod E, Samadi F, Malekzade R, Babaie M, Iranparvar M, Azami A. Four-Year Survival Rate of Patients with Upper GI Cancer in Ardabil . J Ardabil Univ Med Sci 2005;5:180-4. 
14. Biglarian A, Hajizadeh E, Gohari MR. Survival analysis of patients with gastric adenocarcinomas and factors related. Kowsar J 2007;2:345-55.

15. Akoh JA, Macintyre IM. Improving survival in gastric cancer: review of 5-year survival rates in English language publications from 1970. Br J Surg 1992;79:29399. doi:10.1002/bjs. 1800790404

16. Landry J, Tepper JE, Wood WC, Moulton EO, Koerner F, Sullinger J. Patterns of failure following curative resection of gastric carcinoma. Int J Radiat Oncol Biol Phys 1990;19:1357-62. doi: 10.1016/0360-3016(90)90344-J

17. Cuschieri A, Weeden S, Fielding J, Bancewicz J, Craven J, Joypaul V, et al. Patient survival after D1 and D2 resections for gastric cancer: long-term results of the MRC randomized surgical trial. Surgical Co-operative Group. $\mathrm{Br}$ J Cancer 1999;79:1522-30. doi:10.1038/sj.bjc.6690243

18. Dassen AE, Lemmens VEPP, van de Poll-Franse LV, Creemers GJ, Brenninkmeijer SJ, Lips DJ, vd Wurff AAM, Bosscha K, Coebergh JWW. Trends in incidence, treatment and survival of gastric adenocarcinoma between 1990 and 2007: a population-based study in the Netherlands. Eur $J$ Cancer 2010;46:1101-10. doi:10.1016/j.ejca.2010.02.013

19. Agolli L, MauriziEnrici R, Osti MF. Adjuvant radiochemotherapy for gastric cancer: Should we use prognostic factors to select patients. World $J$ Gastroenterol 2016;22:1131-8. doi:10.3748/wjg.v22.i3.1131

20. Fiorica F, Cartei F, Enea M, Licata A, Cabibbo G, Carau B. The impact of radiotherapy on survival in resectable gastric carcinoma: A meta-analysis of literature data.Cancer Treat Rev 2007;33:729-40. doi:10.1016/j.ctrv.2007.08.005 